\title{
Sabores e amores na cozinha de Laura Esquivel
}

\author{
Foods and affections in Laura Esquivel's kitchen \\ Jenison Alisson dos Santos \\ Ana Cristina Marinho Lúcio \\ Universidade Federal da Paraíba - João Pessoa, PB, Brasil
}

\begin{abstract}
Resumo: O presente artigo propõe uma análise do romance Como água para chocolate, de Laura Esquivel, numa perspectiva afetiva, com o objetivo de demonstrar como a autora mexicana utiliza recursos gastronômicos em sua narrativa para recodificar e ressignificar a expressão de sentimentos de suas personagens, como amor, ódio, austeridade e ressentimento. Abordar o romance de Esquivel a partir do escopo proposto nos permite identificar a comida e seu consumo não apenas isoladamente como um processo biológico, mas também como uma possibilidade de perceber, sentir e ler o mundo e as relações interpessoais através de uma ressonância emocional oferecida pelo dado culinário. É igualmente relevante apontar o caráter subversivo que o elemento gastronômico proporciona à diegese, uma vez que é a partir do manuseio da comida que a personagem principal, Tita De la Garza, constrói suas subjetividades e encontra a sua própria voz em um espaço de opressão.
\end{abstract}

Palavras-chave: Laura Esquivel; Como água para chocolate; Comida; Afeto

\begin{abstract}
This article proposes an analysis of Like water for chocolate, novel by Laura Esquivel, through an affective perspective, with the objective of demonstrating how the Mexican author make use of the gastronomic resources in her narrative to recode and resignify the expression of feelings by her characters, such as love, hate, austerity and resentment. Approaching Esquivel's novel through the affective scope allows us to recognize food and its consumption not only as a biological process, but also as a possibility to perceive, feel and read the world and the interpersonal relations through an emotional resonance enabled by the culinary presence. It is equally relevant to identify the subversive aspect given to the diegesis by the gastronomic element, once it is through the handling of food that the protagonist, Tita De la Garza, forges her subjectivities and finds her own voice in an oppressive space.
\end{abstract}

Keywords: Laura Esquivel; Like water for chocolate; Food; Affect

\section{Introdução}

Embora a comida seja comumente associada apenas ao processo biológico de nutrir o corpo, é incontestável que ela está enraizada nas mais diferentes formas de construção sociocultural. As experiências que o sujeito vive em sua trajetória estão sempre demarcadas pela presença do alimento, pelo seu cheiro, por suas texturas e pelas mais diversas emoções que essas sensações podem provocar.

Como água para chocolate (1993), best-seller mexicano escrito por Laura Esquivel, tem como um dos principais tropos narrativos a utilização da comida em um paralelo entre alimento e afetividade. Uma vez que Tita De la Garza - a protagonista da narrativa - é inserida no espaço da cozinha como forma de punição por sua mãe, a personagem encontra nesse espaço a sua liberdade para transmitir suas emoções, desejos e sentimentos para aqueles que comem a comida por ela preparada.

Se nós somos aquilo que comemos, em Como água para chocolate essa popular expressão atribuída a Hipócrates ganha expressiva relevância. Na narrativa, a comida, além de apresentar uma função estética, enquanto artifício simbólico, funciona como um alicerce que concretiza sentimentos metafísicos no universo de Tita, que se tornam perceptíveis através dos códigos gastronômicos 
atribuídos à personagem desde a mais tenra idade. Nosso objetivo no presente artigo é demonstrar como Esquivel articula o diálogo entre a presença da comida e as relações afetivas entre as personagens da narrativa.

\section{Os sabores e amores na cozinha de Esquivel}

Na sociedade contemporânea, o sujeito expressa suas aspirações, suas emoções, suas subjetividades e sua necessidade de conexão com outros indivíduos das mais variadas formas: dogmas religiosos, relações sexuais, pertencimento a tribos ou comunidades, e os prazeres da mesa. É pertinente perceber como a comida se faz presente nas formas de relação interpessoal mencionadas, extrapolando o lugar-comum da mesa e da cozinha, seja na configuração de uma hóstia ou do pão e vinho representantes do corpo e sangue de Cristo, seja pelo uso da comida como forma de estimular o parceiro no ato sexual, ou até mesmo a comida como código sociocultural (a exemplo dos sujeitos veganos).

De acordo com Sarah Sceats (2003, p. 1) em Food, consumption and the body in contemporary women's fiction,

Comer é uma atividade fundamental. É, de certa forma, a primeira coisa que fazemos [ao nascer], a fonte primária de prazer e frustração, a plataforma de nossa mais tenra educação e aprendizado cultural. A comida é o nosso âmago, necessário para a nossa sobrevivência e intrinsecamente conectada às funções sociais ${ }^{1}$.

Levando em consideração a reflexão da autora, a comida e o ato de comer estão tão arraigados em nossa vida que se torna natural que a sua influência se estabeleça como uma força que influencia de forma significativa como interagimos com o mundo - incluindo aí a produção artística.

É de conhecimento comum que as sonatas de Beethoven e as músicas de Marisa Monte são consideradas uma forma de arte; as pinturas de Vermeer e as esculturas de Michelangelo são consideradas algumas das mais belas produções artísticas dos últimos séculos; o mesmo pode ser dito dos romances de Jane Austen ou dos poemas de Emily Dickinson, assim como dos filmes de Woody Allen e das animações de Hayao Miyazaki. Então, por que os pratos preparados pela chef Paola Carosella ou aqueles produzidos por nossas mães não recebem o mesmo

\footnotetext{
"Eating is a fundamental activity. It is more or less the first thing we do, the primary source of pleasure and frustration, the arena of our earliest education and enculturation. Food is our centre, necessary for survival and inextricably connected with social function". Tradução nossa, assim como as demais presentes no artigo.
}

status? Afinal, a comida está tão presente no nosso dia a dia que acabamos por não lhe dar o seu devido valor: por vezes esquecemos que um prato de comida pode ser tão comovente quanto uma música, seja pela reminiscência de um ente querido ou pela emoção de dividir um momento com o seu parceiro em meio a um jantar; da mesma maneira, a comida pode nos trazer o aborrecimento de chegar salgada demais à nossa mesa em um restaurante, assim como o plot twist de um filme pode nos decepcionar. Então, considerando que a comida é um código cultural e que são exigidas de quem a prepara certas habilidades e saberes especiais, não podemos excluir a gastronomia desse patamar artístico.

Não nos é estranho, inclusive, que a comida enquanto temática e problemática permeie a própria criação artística. Podemos perceber a sua presença na pintura (a exemplo de algumas das telas de Franz Snyder e "The Milkmaid" de Vermeer), no teatro (a exemplo do musical Waitress, com texto dramático de Jessie Nelson e música de Sara Bareilles) e na música (a exemplo de "Strawberry Fields Forever" dos Beatles e "Yes Nós Temos Bananas" de Ney Matogrosso). No campo audiovisual, temos uma profusão de reality shows (a exemplo de Masterchef e Bake Off Brasil), séries (a exemplo de Young \& Hungry), documentários (a exemplo de Chef's Table e Cooked), e filmes (a exemplo de Julie \& Julia, de Nora Ephron e A festa de Babette, de Gabriel Axel). Na literatura, a comida é tema de romances aclamados, como $A$ mulher comestivel, de Margaret Atwood, Chocolat de Joanne Harris, e Como água para chocolate, de Laura Esquivel - o nosso objeto de análise.

Um dos maiores bestsellers da literatura mexicana em escala internacional, Como água para chocolate se apresenta como um híbrido entre livro de receitas e romance que se propõe a narrar a história de uma geração da família De la Garza em meio à Revolução Mexicana no início do século XX, a partir das experiências afetivas e gastronômicas de Tita, que possui um fardo a carregar - por ser a mais nova das filhas, a personagem estará encarregada de cuidar de sua mãe até o fim de sua vida. O romance se divide em doze receitas, em que cada uma é referente a um mês na vida de Tita e a comida, e o preparo da mesma, são representativos de momentos significativos na vida da protagonista.

Como água para chocolate é movido pelas relações afetivas - a começar pelo próprio título: "como água para chocolate" é uma expressão popular mexicana que significa estar furioso, em ponto de ebulição (com base na metáfora do preparo da bebida achocolatada, em que a água precisa estar fervendo para adicionar o chocolate). $\mathrm{Na}$ narrativa, entretanto, tal expressão ganha também nuances de cunho sensual, metaforizando o desejo à flor da pele que transpassa os dois personagens centrais - Tita 
e Pedro Muzquiz- em meio às adversidades que ambos enfrentam. Relações afetivas - sua manifestação, sua repressão, sua inexistência - metaforizadas através da comida afetam não só a Tita, mas a todos os personagens da trama, em especial sua mãe Elena e suas irmãs Rosaura e Gertrudis.

O romance se inicia com a narradora - a sobrinhaneta de Tita, filha de Esperanza e que recebe o apelido de "Tita" em homenagem a sua tia-avó - explicando um truque aprendido no livro de receitas escrito pela protagonista para cortar cebolas sem chorar. A narradora nos revela que tal livro foi a única coisa que restou após o trágico fim de Tita, encontrado "[...] sob os restos do que foi o rancho este livro de cozinha que [Esperanza] me deixou de herança ao morrer e que narra, em cada uma de suas receitas, esta história de amor [...]" (ESQUIVEL, 1993, p. 204). É pertinente perceber que, a partir da materialização do livro de receitas na diegese, o mesmo ganha um duplo significado:

[a partir da presença do livro de receitas] a narrativa introduz o [leitor] no nível da história e no do discurso. Como enunciado diegético, a imagem icônica semantiza a ação, a ser desempenhada pela personagem-narradora, de preparar um alimento, a partir de uma receita; como enunciado discursivo, ela constitui a base do relato e de sua divisão episódica, já que conjuga o registro de receitas ao registro da história [...]. Em consequência disso, o livro de receita é também um diário, que, como documento, garante a legitimidade do narrado [...] (SARAIVA, 2000, p. 67).

Podemos inferir, a partir da observação de Saraiva, que o livro de receita é o canal que permite narradora e leitor tomarem conhecimento dos acontecimentos da vida de Tita e, em segundo plano, da Revolução Mexicana. A "divisão episódica" da narrativa, uma fragmentação circunstancial em forma de receitas que representam eventos importantes na vida da protagonista, subvertendo com a tradição de linearidade, promove um movimento fragmentado do tempo narrativo e marca, através da presença da comida, esse deslocamento temporal.

É relevante ressaltar também o dado afetivo da sobrinha-neta de Tita como narradora da história. Visto que se trata de uma narrativa sobre gerações, tradições e relações entre os indivíduos e a comida, ao incorporar a narradora na diegese, Esquivel estabelece um vínculo entre a narradora e a história a ser contada e, consequentemente, evoca no leitor o sentimento de cumplicidade e empatia para com a história. Não apenas isso, mas tal vínculo afetivo é reforçado ao final do romance, quando a narradora conclui a sua história e menciona que, assim como a sua mãe Esperanza, ela deu continuidade à tradição culinária de Tita uma vez que ela “[...] continuará vivendo enquanto houver alguém que cozinhe suas receitas" (ESQUIVEL, 1993, p. 205).

A narradora então prossegue ao contar o momento em que Tita nasce, prematuramente, por não conter o seu choro, ainda no ventre da mãe, quando a mesma estava a cortar cebolas, registrando que desde o seu primeiro suspiro a protagonista possui um vínculo especial não só com a comida, mas também com o espaço da cozinha. Todavia, se Tita está fortemente ligada a esse espaço, ela também chorava pelo seu destino premeditado de cuidar da mãe até o dia de sua morte - uma tradição que acomete a filha mais nova da família De la Garza por gerações.

É relevante notar que essa associação entre Tita desde os seus primeiros momentos de vida - e o espaço da cozinha acaba por desenvolver de forma significativa na personagem o que Brillat-Savarin considera ser o nosso sexto sentido - o gosto. Se, para o filósofo francês, o gosto "[...] tem por finalidade a conservação do indivíduo", ele é "incontestavelmente um sentido, [e] com mais razão ainda deve-se atribuir esse título aos órgãos destinados à conservação da espécie" (BRILLAT-SAVARIN, 1995, p.34). Para tanto, tendo em vista que o gosto tem como incumbência a preservação dos sujeitos enquanto espécie, Brillat-Savarin atribui a esse sentido uma fusão dos ímpetos sensuais, sensoriais e sexuais, que ele denomina como genésico, e que percebemos ser o elo entre Tita, a comida e a maneira como ela a usa para expressar seus desejos, seus sentimentos e a sua subjetividade no decorrer da narrativa.

Após o nascimento de Tita, seu pai vai a óbito repentinamente. Se, "para a maioria das pessoas a conexão entre comida e amor é intermediada pela mãe, como regra a pessoa mais importante no mundo de uma criança, capaz de oferecer [...] tudo que sustenta, nutre, preenche, completa"2 (SCEATS, 2003, p. 11), Elena se vê incapaz de amamentar seu bebê ou criar qualquer vínculo com a filha após o choque de sua repentina viuvez, e a coloca sob os cuidados de Nacha, a índia nativa e cozinheira da família. Contudo, a mãe de Tita a via como uma servente a cumprir uma tradição familiar. Tita cria um laço maternal com Nacha, que lhe ensina os segredos pré-hispânicos da arte culinária, e, ultimamente, acaba estabelecendo a personagem de uma vez por todas no espaço culinário sob a aprovação de Mamãe Elena. É a partir do compartilhamento do espaço da cozinha e do fazer culinário que Nacha proporciona a Tita o que sua mãe almeja tirar: autonomia para expressar sua potencialidade criativa - e, por que não, artística - e sua subjetividade através dessa nova linguagem proporcionada pela comida.

\footnotetext{
"For many people the connection of food with love centres on the mother, as a rule the most important figure in an infant's world, able to give $[\ldots]$ everything that sustains, nourishes, fulfils, completes.
} 
Torna-se pertinente, então, promover um diálogo entre $\mathrm{o}$ ato de alimentar como supostamente inerente ao sujeito materno problematizado por Esquivel em Como água para chocolate e a proposta de Sceats de que "a transposição dos aspectos de criar e alimentar da maternidade para figuras substitutas é uma maneira de evitar essencialismos biologicamente determinados [...]"3 (SCEATS, 20013, p. 15). Ou seja, para a estudiosa, o mais relevante propósito de oferecer alimento ao outro nas mais diversas representações artísticas não se constitui como um ato biológico, mas sim como ato simbólico.

Em oposição ao já mencionado acolhimento de Tita por Nacha e o vínculo afetivo que ambas criaram a partir do compartilhamento do espaço da cozinha, percebemos uma divergência na representação de Elena nesse mesmo ambiente. Embora sempre supervisionando, a matriarca dos De la Garza não participa ativamente dos afazeres culinários do rancho; mas, quando o faz, o leitor pode perceber que a maneira como ela lida com os alimentos reflete sua postura perante suas filhas e empregadas: de forma ríspida e mecanizada. E se a comida produzida na cozinha de Esquivel é um símbolo de desejo e subversão, o leitor notará que Elena é incapaz de apreciar as iguarias preparadas por Tita - não apenas isso, mas a apatia para com as comidas preparadas por sua filha é o que culmina na sua morte. Assim, o desprazer pela comida sentido por Elena caracteriza-se pelo desejo de suprimir a sua natureza transgressora, de desafiar as tradições que uma vez fizeram parte do seu passado, ao trair o esposo e ter uma filha (Gertrudis) com um homem negro.

Dessa forma, uma vez que a narrativa se desdobra a partir das vivências de Tita calcadas pela frieza tirânica de Elena, temos, em contrapartida, as tradições préhispânicas da subversiva Nacha, que fazem o leitor perceber como positivo o distanciamento entre a mãe biológica e a protagonista, e o acolhimento da mãe adotiva no espaço da cozinha, uma vez que é nesse espaço e através da comida que Tita passa a ter uma voz, adquirir saberes e construir suas próprias subjetividades - simbolizando sua liberdade, mesmo que em um espaço de suposto confinamento.

Os desafetos entre Tita e sua mãe se intensificam na diegese quando a tradição familiar mantida por Elena vem à tona, uma vez que o então namorado de Tita, Pedro Muzquiz, deseja pedir a mão da moça em casamento. Todavia, Elena sequer permite que o rapaz realize o pedido e lembra a Tita: "Pois mais vale que lhe informes que se é para pedir tua mão, não o faça. Perderia seu tempo e me faria perder o meu. Sabes muito bem que por ser a mais jovem das mulheres te corresponde cuidar

\footnotetext{
3 "The transposing of the nurturing, feeding aspects of motherhood onto substitute figures is a way of avoiding a biologically determined essentialism $[\ldots]^{\prime \prime}$
}

de mim até o dia de minha morte" (ESQUIVEL, 1993, p. 8). Não contente em negar a Tita a chance de se casar com o amor de sua vida, Mama Elena oferece a mão de sua outra filha, Rosaura, para casar-se com Pedro sendo que o último aceita a proposta da matriarca com a justificativa de "[casar-se] sentindo um imperecível amor por Tita" (ESQUIVEL, 1993, p. 12), usando seu enlace com Rosaura para continuar próximo à amada. Ademais, Elena ainda encarrega Tita das preparações culinárias da festa de casamento de Pedro e Rosaura "[...] como castigo por não ter querido estar presente no dia em que foram pedir a mão de sua irmã Rosaura, pretextando uma enxaqueca" (ESQUIVEL, 1993, p. 21). É pertinente levar em consideração este momento da diegese por nos possibilitar perceber que Elena é colocada numa posição que acaba por perpetuar a opressão patriarcal naquele espaço, visto que ela opera de modo a subjugar os seus - Tita especialmente - para manter a estabilidade de seu poder e de suas ordens.

Uma vez que na narrativa de Esquivel a comida não é apenas comida, mas um fio condutor para expressar emoções, a diegese ganha uma pitada de realismo mágico quando o bolo que Tita prepara para o casamento de sua irmã é acidentalmente contaminado pelas lágrimas que ela derrama, “ $[\ldots]$ e alterado com elas a textura do nogado" (ESQUIVEL, 1993, p.28), ao contemplar a impossibilidade de ser feliz ao lado de Pedro.

Nos aliamos a Highmore (2010) em "Bitter after taste: affect, food and social aesthetics" para melhor compreender a relação entre comida, sabor e afetividade. Segundo o estudioso,

Aqui é onde cada sabor possui uma ressonância emocional (doçura, acidez, amargura). Aqui, a arena biocultural da aversão (especialmente a aversão a alimentos ingeridos ou parcialmente ingeridos) simultaneamente evoca uma forma de percepção sensitiva, um registro afetivo de vergonha e desdém, mas também de recuo corporal. Quando emoções são descritas como sabores, entretanto, elas são simples convenções metafóricas? Ou a condição emocional de amargura, por exemplo, libera a mesma resposta gástrica de quando ingerimos sabores amargos? ${ }^{4}$ (HIGHMORE, 2010, p. 120).

A partir da reflexão de Highmore, podemos perceber que a comida não só faz parte de um processo biológico, mas configura também um meio de estabelecer formas de

\footnotetext{
4 "This is where every flavor has an emotional resonance (sweetness, sourness, bitterness). Here the bio-cultural arena of disgust (especially disgust of ingested or nearly ingested foods) simultaneously invokes a form of sensual perception, an affective register of shame and disdain, as well as bodily recoil. When emotions are described by flavors, though, are these simply metaphorical conventions? Or does the emotional condition of bitterness, for instance, release the same gastric response as the ingestion of bitter flavors?"
} 
transmitir desejos e sentimentos nas relações interpessoais a partir de "uma ressonância emocional", ganhando assim dimensões físicas e metafóricas. Em Como água para chocolate, essa condução de emoções através da comida ganha força quando os convidados do casório de Rosaura e Pedro, após comerem o bolo alterado pelas lágrimas de Tita, sentem que "[...] uma imensa nostalgia se apossava de todos [...] e inclusive Pedro, sempre tão seguro, fazia um esforço tremendo para conter as lágrimas" (ESQUIVEL, 1993, p. 31). Não apenas isso, mas "o pranto foi o primeiro sintoma de uma intoxicação estranha que tinha algo a ver com uma grande melancolia e frustração que [...] fez com que eles terminassem no pátio, nos currais e nos banheiros, cada um com saudade do amor de sua vida" (ESQUIVEL, 1993, p. 32). As lágrimas carregadas da mais forte das emoções na preparação de algo tão simples quanto um bolo foram capazes de fazer todos os presentes sentirem, de forma literal, o poder devastador do amor perdido e a profunda tristeza que Tita estava sentindo.

Após o casamento, a disputa entre Rosaura e Tita pelo amor de Pedro torna-se o ponto de ebulição da narrativa. É interessante perceber como os laços afetivos das duas personagens com o rapaz são traduzidos no espaço da cozinha. Uma vez que Pedro admite para a protagonista que se casou com Rosaura "[...] para estar perto [de Tita], a mulher que verdadeiramente [ama]" (ESQUIVEL, 1993, p. 30), o mesmo utiliza a desculpa da indigestão causada pelo banquete do casamento para não consumar as núpcias com sua esposa.

Após alguns meses de adiamento, Rosaura e Pedro finalmente têm sua primeira relação sexual, apesar da relutância do rapaz: "Pedro até esse momento compreendeu que não podia recusar-se a realizar sua tarefa de reprodutor por mais tempo [...]" (ESQUIVEL, 1993, p.33). A consumação é bastante desapaixonada e carregada de humor irônico, visto que ao mencionar para seu esposo que já se sente melhor da intoxicação causada pelo bolo e dizer que já se sente pronta, Pedro inicia uma oração, enquanto no ato "[...] utilizavam o lençol nupcial, que só deixava visíveis as partes nobres da esposa. Terminando o ato, [Pedro] afastava-se antes que esta se descobrisse" (ESQUIVEL, 1993, p. 46).

A falta de paixão de Rosaura, já demonstrada em sua relação com Pedro, fica evidente pela falta de habilidade no ato de cozinhar (assim como pela não apreciação das comidas feitas por Tita e, posteriormente, pela impossibilidade de amamentar seu próprio filho). Certo dia, na tentativa de impressionar Pedro no espaço dominado por Tita, a irmã mais velha da protagonista se propõe a cozinhar. O resultado não poderia ser diferente: "Obviamente o arroz virou papa, a carne ficou salgada demais e a sobremesa quase queimou. Ninguém na mesa se atreveu a mostrar nenhum gesto de desagrado [...].
É claro que [...] toda a família passou mal do estômago" (ESQUIVEL, 1993, p. 40). É interessante perceber como, diferentemente da protagonista, a autora escolhe destituir Rosaura de ação no espaço da cozinha, não descrevendo para o leitor o preparo da sua refeição, mas escolhe nos mostrar o resultado desastroso, com uma comida tóxica, sem vida e uma resposta negativa das pessoas sentadas à mesa. Se "[...] a comida é o sine qua non da função afetiva do gosto"5 (HIGHMORE, 2010, p. 126, grifo nosso), ao levar em consideração a sequência dos acontecimentos, o leitor irá notar que a péssima refeição produzida por Rosaura sobrepõe-se à falta de afetividade não só ao produzi-la, mas pela falta de amor por Pedro e, progressivamente, pela incapacidade de nutrir afetivamente e fisiologicamente - seu filho, sendo sua natureza ligada não ao amor, mas ao dejeto.

Em contrapartida, Esquivel estabelece em sua narrativa, através de Tita, o poder afetivo proporcionado pela comida e pelo fazer culinário sob uma luz positiva. Com o pretexto de comemorar um ano desde que Tita assumira a cozinha da família em consequência da morte de Nacha no casamento de Rosaura, Pedro toma a coragem de entregar, diante de Elena e de sua esposa grávida, um ramalhete de rosas para Tita. Percebendo o constrangimento da filha, que se retira do recinto, "Mamãe Elena, com um único olhar, ordenou a Tita sair da sala e desfazer-se das rosas" (ESQUIVEL, 1993, p. 38). No caminho de cumprir com a ordem da matriarca, a moça abraça as rosas com tamanha força que "[...] quando chegou à cozinha, as rosas, que em princípio eram cor-derosa, já tinham se tornado rubras pelo sangue das mãos e do peito de Tita" (ESQUIVEL, 1993, p. 38). Antes de jogálas fora, entretanto, a voz de Nacha ressona na cozinha, lembrando a Tita uma receita pré-hispânica de codorna ao molho de rosas - ratificando que os laços afetivos entre as duas, forjados pela conexão com a comida e com o espaço da cozinha, transcendem o plano terreno.

É pertinente perceber que aqui as rosas ganham um duplo significado: de acordo com Chevalier e Gheerbrant (1986, p. 891-893) em Diccionario de los símbolos, a rosa simboliza não só o amor puro - aqui demonstrado pelo amor que Pedro sente por Tita e pelo amor maternal entre a protagonista e a índia Nacha -, mas simboliza também o renascimento e o divino, uma referência a Cristo e ao sangue de suas chagas - aqui reificado pelo renascimento da chama do amor entre Pedro e Tita, e pelo contato da mesma com Nacha num plano espiritual, oferecendo uma dimensão mística à receita de Tita e evidenciando o teor de realismo mágico para o leitor.

É relevante apontar como, mais uma vez, Esquivel coloca em perspectiva a relação de Tita com as duas

\footnotetext{
"[...] food is the sine qua non of taste's affective function".
} 
figuras maternas presentes em sua vida: Elena e Nacha. Se Nacha, mesmo depois de falecida, entrelaça-se na vida de Tita agindo como um guia espiritual - tão forte é o elo afetivo entre ambas -, a presença castradora e opressiva de Elena pode ser sentida onde quer que a cozinheira esteja - especialmente enquanto prepara seus alimentos, a exemplo de quando Tita está preparando as codornas para cozinhá-las:

Nesse momento pensou no bom que seria ter a força de Mamãe Elena. Ela matava assim, de uma cutilada só, sem piedade. Bom, ainda que pensando bem, não. Com ela tinha feito uma exceção, tinha começado a matá-la desde criança, pouco a pouco, e ainda não lhe dera o golpe final (ESQUIVEL, 1993, p. 39).

Podemos observar que Elena é colocada na posição de robustecer as amarras de um regimento patriarcal opressor e violento - física e emocionalmente - que tem por finalidade marginalizar e punir a natureza transgressora de sua filha, na intenção de "impor ordem ou prevenir os danos do caos interno [...], isolando [esse dano] num espaço, dessa forma tornando-o inócuo"6 (TUAN, 2013, p. 187), tornando, finalmente, Tita em um sujeito que vive à margem da sociedade representada pelo rancho dos De la Garza. Tita, entretanto, encontra, em meio à presença dominadora da mãe, sua própria voz subversiva através de suas receitas e do preparo de suas comidas.

A justaposição dos elos afetivos entre Rosaura e Tita em relação a Pedro é demarcada na narrativa de forma categórica a partir da reação dos personagens em relação à codorna servida com um molho das pétalas das rosas. Em um ambiente ainda carregado de tensão promovida pela infeliz refeição servida por Rosaura que será inevitavelmente comparada à de Tita - e pelo audacioso presente que Pedro ofereceu a Tita, a comida da moça causa comoção entre os membros da família. Sem se conter, Pedro afirma estar degustando "um prazer dos deuses" (ESQUIVEL, 1993, p.41), que desperta a reprovação de Elena na forma de uma crítica sobre a comida servida, e de Rosaura, que se retira da mesa sob o pretexto de estar passando mal.

Entretanto, a fusão do sangue de Tita com as pétalas de rosas proporciona ao momento uma manifestação explícita do desejo latente entre ela e Pedro. A narradora enuncia que "parecia que tinham descoberto um novo código de comunicação no qual Tita era a emissora, Pedro o receptor e Gertrudis a felizarda em quem se sintetizava esta singular relação sexual através da comida" (ESQUIVEL, 1993, p.42). O amor de Tita por Pedro é traduzido na alquimia culinária que resulta na

\footnotetext{
6 "imposing order or forestalling the dangers of internal chaos [...], [said danger] is isolated in space, thereby rending it innocuous".
}

codorna ao molho das rosas, transformando o que seria um simples alimento em uma força motriz carregada de erotismo. Quando ingerida, a codorna se reconfigura em um intenso afrodisíaco, fazendo com que os personagens sintam uma forte e calorosa onda de excitação.

Sobre o erotismo em consonância com as relações afetivas apresentado no romance, acreditamos ser pertinente nos apoiar em Audre Lorde (2013) e em seu texto "Uses of the erotic: the erotic as power" para melhor compreender como Esquivel estabelece essa dinâmica. De acordo com a estudiosa, o erotismo - e a ideia de dissimulação, da desvalorização e da vulgarização que o acompanha - é um construto social criado pelo patriarcado para oprimir a imagem da mulher e sua própria sexualidade, conferindo-lhe um poder que, por ameaçar a própria essência masculina (ego e sexualidade), paradoxalmente se volta contra essa mulher "sedutora". Para Lorde, o erótico é um termo "[...] mal interpretado pelos homens para ser usado contra as mulheres"7 (LORDE, 2013, p. 54).

A partir dessa perspectiva, é notória a intenção da autora de subverter esse paradigma ao representar a subjetividade erótica do sujeito feminino sob uma luz positiva, desvinculando-se de uma visão tipicamente masculina (machista) do erótico como viés de depreciação do sujeito e de opressão da sexualidade feminina representado de forma significativa na narrativa por Elena, que é punida por tal postura ao morrer de forma solitária e sem amor. Dessa forma, voltamo-nos a Lorde (2013) para estabelecer que essa desconstrução da percepção do erotismo do sujeito feminino proposta por Esquivel se caracteriza como uma forma de representação de poder social, mas que também é político, econômico e acadêmico, articulando a subversão do imaginário social e consolidando o erotismo como não necessariamente relacionado apenas ao sexo, mas a todo um espectro de sentimentos que vivenciamos ao praticar qualquer atividade tão intensamente como sentiríamos se estivéssemos praticando o ato sexual:

O erótico funciona $[. .$.$] de diversas maneiras, e$ a primeira vem com o poder que esse erotismo proporciona em consonância com a partilha de qualquer interação com outra pessoa. Compartilhar alegria, seja física, emocional, ou intelectual, gera uma ponte entre os indivíduos servindo como uma base para entender o que não é compartilhado entre eles, diminuindo assim a ameaça da diferença ${ }^{8}$ (LORDE, 2013, p. 56).

\footnotetext{
"[...] misnamed by men and used against women".

8 "The erotic functions [...] in several ways, and the first is in providing the power which comes from sharing deeply any pursuit with another person. The sharing of joy, whether physical, emotional, psychic, or intellectual, forms a bridge between the sharers which can be the basis for understanding much of what is not shared between them, and lessens the threat of their difference".
} 
Podemos entender, a partir da perspectiva de Lorde (2013), que o ato de cozinhar - que é uma atividade característica dessa mulher "sedutora", de acordo com as convenções da sociedade patriarcal - em Como água para chocolate configura-se como uma atividade erótica, uma vez que ela desperta o prazer e a interação entre os personagens da narrativa.

Ainda, nota-se que Elena tenta infrutiferamente negar tal sentimento afirmando, sem muita convicção, que a comida está demasiadamente salgada, enaltecendo a repressão de sentimentos e das relações afetivas da matriarca, que perpassa até seus últimos dias de vida. É pertinente observar também a reação de Rosaura diante dessa manifestação espontânea de emoções: a esposa de Pedro, assim como sua mãe, resiste ao arrebatamento pelo sentimento de paixão provocado pelas codornas e se retira da mesa com a justificativa de estar passando mal. O leitor notará que sua recusa de permanecer na mesa e sofrer um efeito similar aos demais significa também uma recusa à paixão e ao amor. Logo após a rejeição, Rosaura se entrega à doença, e essa entrega da personagem reverbera no decorrer do romance, visto que após a morte de sua mãe Rosaura passa a utilizar o mesmo penteado e as mesmas roupas de tons escuros, representando a perpetuação das tradições antiquadas da família De la Garza, ao mesmo tempo que reprova a natureza subversiva de Tita. Se Elena morreu por não querer comer as comidas preparadas por Tita, Rosaura morreu por consequência de severos problemas intestinais, comprovando ser incapaz de nutrir qualquer sentimento afetivo positivo - seja em relação a seus filhos, marido ou irmã.

Finalmente, é relevante notar as consequências causadas na personagem Gertrudis após sua participação enquanto receptáculo da manifestação do desejo entre Tita e Pedro através da codorna ao molho de rosas. Após ser a mediadora de uma inesperada relação entre os amantes, o ardor da paixão entre os dois manifestado através de Gestrudis não se dissipou:

A única coisa que a animava era a ilusão do refrescante banho que a esperava, mas desgraçadamente não o pôde desfrutar, uma vez que as gotas que caíam do chuveiro não conseguiam tocar-lhe o corpo: evaporavam antes sequer de roçá-la. $\mathrm{O}$ calor que se desprendia de seu corpo era tão intenso que as madeiras começaram a estalar e arder. Ante o pânico de morrer incendiada pelas chamas, saiu correndo do quartinho, assim como estava, completamente nua (ESQUIVEL, 1993, p. 44).

Não apenas isso, mas o fogo iniciado pelo corpo de Gertrudis - que a partir dele exala uma fumaça perfumada pelas rosas de Tita - chama a atenção de um soldado villista que estava a lutar contra os federais pelas redondezas e que, instigado pelo odor e pelo sentimento de excitação carregado pela fumaça, vem ao encontro de Gertrudis e a leva do rancho, enquanto consumam o seu desejo ainda em fuga, em cima do cavalo.

Faz-se pertinente que nos apoiemos mais uma vez em Chevalier e Gheerbrant para perceber o duplo significado desta passagem na narrativa. Em um primeiro momento, é estabelecido que o fogo está diretamente ligado à consumação do ato sexual entre Tita e Pedro, uma vez que "a significação sexual do fogo está universalmente ligada à primeira técnica de obtenção do fogo por fricção, em vaivém, a imagem do ato sexual"9 (CHEVALIER; GHEERBRANT, 1986, p. 513). Da mesma forma, o desejo proibido entre Tita e Pedro aqui é codificado e ressignificado através das habilidades gastronômicas de Tita, nas quais o fogo está inerentemente conectado à pratica de cozinhar (MONTANARI, 2013).

Em um segundo momento, o fogo em Como água para chocolate está associado à morte e ao renascimento (CHEVALIER; GHEERBRANT, 1986, p.513). Após a fuga de Gertrudis com o guerrilheiro, Elena "proibiu voltar-se a mencionar o nome da filha e mandou queimar suas fotos e seu registro de nascimento" (ESQUIVEL, 1993, p. 48). Gertrudis está finalmente liberta das amarras opressoras da mãe e se envolve de forma significativa na Revolução, tornando-se uma general das tropas guerrilheiras. É interessante observar como Esquivel, ao ratificar uma personagem feminina saída de um contexto invariavelmente machista e misógino como uma figura de status e poder na rebelião, põe em cheque a ideologia sexista que permeava a época e que ecoa na contemporaneidade. Gertrudis, assim como Tita, são “[...] mulheres da mesma geração que escolheram desafiar, cada uma à sua maneira, antiquados construtos sociais que $[\ldots]$ sua mãe obedecia inquestionavelmente [...]"10 (STANILAND, 2015, p. 59).

\section{Algumas considerações finais}

Como podemos perceber, Como água para chocolate, de Laura Esquivel, apresenta-se como um romance que estabelece diversas maneiras de representação dos (des)afetos através da presença da comida, mostrando-nos como o ato de cozinhar e o espaço da cozinha podem representar algo além da opressão e do aprisionamento do sujeito feminino, mas transformar-se em um

\footnotetext{
9 "La significación sexual del fuego está universalmente ligada a la primera técnica de obtención del fuego por frotamiento, em vaivén, imagen del acto sexual"

10 " $[\ldots]$ women of the same generation who choose to defy, each in their way, the antiquated social mores that $[\ldots]$ her mother unquestioningly follow $[\ldots] "$
} 
ato de subversão, de empoderamento, de liberdade, de amor e de prazer.

A cozinha de Esquivel torna-se um espaço tomado pela inventividade e pelo realismo mágico proporcionado pela presença da comida. Nesse espaço, a Tita é permitido utilizar os seus saberes e sabores culinários para, através do poder de nutrir o corpo e o espírito, dar vida às suas múltiplas subjetividades: seja ela amante, seja ela provedora, seja ela artista.

\section{Referências}

BRILLAT-SAVARIN, Jean Anthelme. A fisiologia do gosto. Trad. Paulo Neves. São Paulo: Companhia das Letras, 1995.

CHEVALIER, Jean; GHEERBRANT, Alain. Diccionario de los simbolos. Barcelona: Editorial Herder, 1986.

ESQUIVEL, Laura. Como água para chocolate. Trad. Olga Davary. São Paulo: Martins Fontes, 1993.

HIGHMORE, Ben. Bitter after taste: affect, food and social aesthetics. In: GREGG, Melissa; SEIGWORTH, Gregory J. (Ed.). The affect theory reader. London: Duke University Press, 2010, p. 118-137.
LORDE, Audre. Uses of the erotic: the erotic as power. In: LORDE, Audre. Sister outsider: essays and speeches. Berkeley: The Crossing Press, 2013. p. 53-59.

MONTANARI, Massimo. Comida como cultura. Trad. Letícia Martins de Andrade. 2. ed. São Paulo: Editora Senac São Paulo, 2013.

SARAIVA, Juracy I. A. O imaginário na representação do amor: Como água para chocolate. In: PINO, Dino del (Org.). Semiótica: olhares. Porto Alegre: EDIPUCRS, 2000. p. 65-76.

SCEATS, Sarah. Food, consumption and the body in contemporary women's fiction. Cambridge: Cambridge University Press, 2003.

STANILAND, Emma. Gender and the self in Latin American literature. London: Routledge, 2015.

TUAN, Yi-fu. Landscapes of fear. Minnesota: University of Minnesota Press, 2013.

Recebido: 15 de abril de 2017

Aprovado: 26 de setembro de 2017

Contato:

Jenison Alisson dos Santos <jenison.alisson@gmail.com> Ana Cristina Marinho Lúcio <anamanho@gmail.com> 